\title{
Epidemiological study of open fractures of the ankle and foot
}

\author{
Leandro Pessoa Carneiro ${ }^{(\mathbb{D})}$, Luiz Augusto Sampaio Gonzaga Filho' (D), Jorge Mitsuo Mizusaki ${ }^{(\mathbb{D}}$, Sergio Damião Santos Prata' ${ }^{(\mathbb{D})}$, \\ Marco Antonio Giglioli Rizzo'
}

1. Hospital Santa Marcelina, São Paulo, SP, Brazil.

\begin{abstract}
Objective: To characterize the epidemiological profile of patients treated at a hospital service with diagnosis of open fracture of the ankle and foot.

Methods: Retrospective, descriptive, epidemiological, observational study of open fractures of the ankle and foot selected by convenience sampling in a hospital service in São Paulo, state of São Paulo, Brazil, from March 1, 2017, to March 1, 2019 , totaling 109 patients. Data collection was conducted for the analysis of variables included in patients' medical records.

Results: The medical records of 700 patients with open fractures were assessed. Of these patients, 13.2\% (109 patients) had open fractures of the ankle and foot. There was a predominance of male young adults (70.8\%) and of left lower limb fractures (51.85\%). Most cases were classified as Gustilo and Anderson type II fractures (42.6\%). Motorcycle accidents (44.45\%) predominated, and students and professional motorcyclists were the most frequent occupations (37.04\%). The most adopted stabilization method was osteosynthesis (internal fixation) (44.45\%), and primary amputation was required in $3.7 \%$ of the cases.

Conclusion: Male young adults were the most affected by fractures of the ankle and foot, and traffic accidents were the leading cause. Most patients had an educational attainment of complete elementary education. Most fractures were classified as Gustilo and Anderson type II. Greater severity was observed in patients with associated injuries in other body segments and who developed early complications during hospitalization.
\end{abstract}

Level of Evidence IV; Prognostic Studies; Case Series.

Keywords: Open fractures/epidemiology; Foot bones; Ankle; Feet.

\section{Introduction}

Traffic accidents have a major negative socioeconomic impact and lead to high public health costs, especially those resulting in open fractures ${ }^{(1,2)}$. After the development of automotive vehicles and motorcycles, there has been a change in the pattern of fractures, characterized by more severe impairment of bones and soft tissues, which cause prolonged hospitalization and recovery periods ${ }^{(3,4)}$.

The incidence of open fractures is estimated at 11.5 per 100,000 people, with lower limb fractures accounting for $40 \%$ of the cases. There have been variations in the epidemiology of fractures of the foot and ankle in different studies and in different regions of Brazil. An epidemiological study conducted in the state of Minas Gerais found that $13.2 \%$ and $5 \%$ of open fractures involved the foot and the ankle, respectively(5). Similar results were observed in the southeast and north region, with involvement of the foot in $11.2 \%$ and $11.5 \%$ of the cases, and of the ankle in $4.8 \%$ and $4.26 \%$ of them, in this $\operatorname{order}^{(6,7)}$. Differences were observed in the state of São Paulo, where involvement of the ankle was more frequent than that of the foot, accounting for $11.27 \%$ and $4.91 \%$, respectively ${ }^{(8)}$.

The treatment of open fractures aims at caring for soft tissue injuries, as well as achieving early stabilization of fracture and preventing infection ${ }^{(9-12)}$.

The aim of this study was to characterize the epidemiologic profile of open fractures of the ankle and foot.
Study performed at the Hospital Santa Marcelina, São Paulo, SP, Brazil.

Correspondence: Leandro Pessoa Carneiro. Rua Santa Marcelina, 177, Vila Carmosina - 08270-070, São Paulo, SP, Brazil. E-mail: leandro.carneiro7@gmail.com. Conflicts of Interest: none. Source of funding: none. Date received: June 23, 2021 Date accepted: July 07, 2021. Online: August 31, 2021.
How to cite this article: Carneiro LP, Gonzaga Filho LAS, Mizusaki JM, Prata SDS, Rizzo MAG. Epidemiological study of open fractures of the ankle and foot. J Foot Ankle. 2021;15(2):150-4. 


\section{Methods}

This study was approved by the Institutional Review Board and registered on the Plataforma Brasil database under CAAE number: 39571320.5.0000.0066.

After study approval by the institutional REC, data were collected using a retrospective, descriptive, observational design. Patients were selected by convenience sampling in the institution.

The study assessed 700 medical records of patients admitted to a high-complexity hospital in the city of São Paulo, state of São Paulo, Brazil, with the diagnosis of open fracture, from March 1, 2017, to March 1, 2019.

All admitted patients diagnosed with open fracture of the foot and ankle were included. Exclusion criteria were patients previously treated at another services or hospitals; those who were admitted more than 6 hours after the accident; cases of hospital evasion and death before the orthopedic procedure; and those who refused to sign the informed consent form (ICF). The final sample consisted of 109 patients.

A data collection instrument was developed to analyze the medical records of patients with open fracture of the ankle and foot, which included questions on gender, affected side, occupation, educational attainment, etiology of trauma, type of pre-hospital care, mean of transportation to the emergency room (ER), day of the week, time of the accident, associated injuries, type of treatment received, length of hospital stay, and infections.

We also sought to investigate the consumption of alcohol or illegal drugs (marijuana, cocaine, crack, heroine, ecstasy, solvents) in the 6 hours preceding trauma. This information was verified from patients' report registered in their medical records, and no additional toxicological tests were performed to confirm these reports. The 6-hour interval may be explained by the average time when alcohol can be identified in blood toxicological tests. Data were collected by orthopedic and trauma residents, orthopedists, and experts in foot and ankle surgery.

Open fractures were classified according to the classification proposed by Gustilo and Anderson (11), which describes associated soft tissue injuries and may partly determine the treatment and prognosis of these injuries. Fractures classified as Gustilo and Anderson type II and III initially underwent debridement, surgical mechanical cleaning, and primary or secondary wound coverage, together with provisional external fixation for stabilization. Similarly, type I fractures received initial care for soft tissues and, depending on type and angle of deviation of the fractures, received conservative treatment with immobilization or subjected to permanent internal fixation.

The collected data were processed through Microsoft Excel spreadsheets, version 2017. Homogeneity between categories of qualitative variables (seasonal distribution, day of the week, time, age, educational level and occupation, type of accident, method of pre-hospital care and transport to hospital, classification of fractures) and the presence of association between these variables were assessed by the Pearson's chi-square test using the SPSS 20.0 software. All tests considered a level of significance of $5 \%(\alpha=0.05)$, with statistical significance set at $\mathrm{p}<0.05$.

\section{Results}

Open fractures of the foot and ankle accounted for $15.6 \%$ (109 fractures) of overall fractures. The most prevalent age group was that from 21 and 30 years, with statistical significance $(p<0.001)$, and mean age was 28.21 years (Figure 1). There was a predominance of men (70.8\%) and involvement of the left side (51.85\%). Motorcycle accidents predominated (44.45\%), followed by running overs (14.82\%) (Table 1). The most frequent occupations were students (26.92\%) and professional motorcyclists (15.4\%) (Table 2 ), and most patients had an educational attainment of complete elementary education (59\%) (Figure 2). It was found that $14.82 \%$ of the cases were repeated cases.

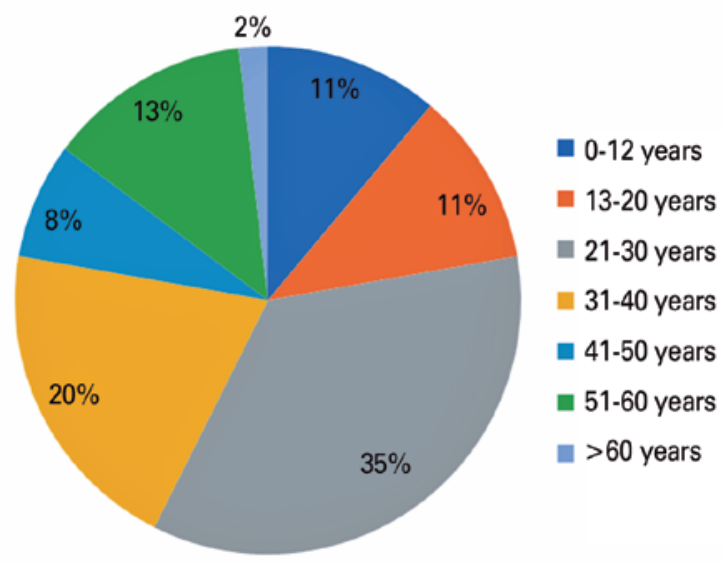

Figure 1. Patients' distribution by age group.

Table 1. Distribution by occupation

\begin{tabular}{lc}
\hline Occupation & Percentage (\%) \\
\hline Student & 26.92 \\
\hline Motorcyclist & 15.40 \\
Construction industry & 10.52 \\
\hline Trade industry & 7.60 \\
\hline Retired & 6.43 \\
Manufacturing & 6.14 \\
\hline Self-employed & 5.55 \\
\hline Security industry & 3.50 \\
\hline Unemployed & 2.63 \\
\hline Housekeeper & 1.75 \\
Transportation industry & 1.75 \\
\hline Agriculture & 1.16 \\
\hline Other & 10.59 \\
\hline
\end{tabular}


Table 2. Distribution by trauma etiology

\begin{tabular}{lc|}
\hline Etiology & Percentage \\
\hline Motorcycle accident & 44.45 \\
\hline Running over & 14.82 \\
Smashing & 11.10 \\
Fall from height & 11.12 \\
Automobile accident & 5.56 \\
Fall from one's height & 3.7 \\
Bicycle accident & 3.7 \\
Firearm wound & 1.85 \\
\hline Physical aggression & 1.85 \\
\hline Sports activity & 1.85 \\
\hline
\end{tabular}

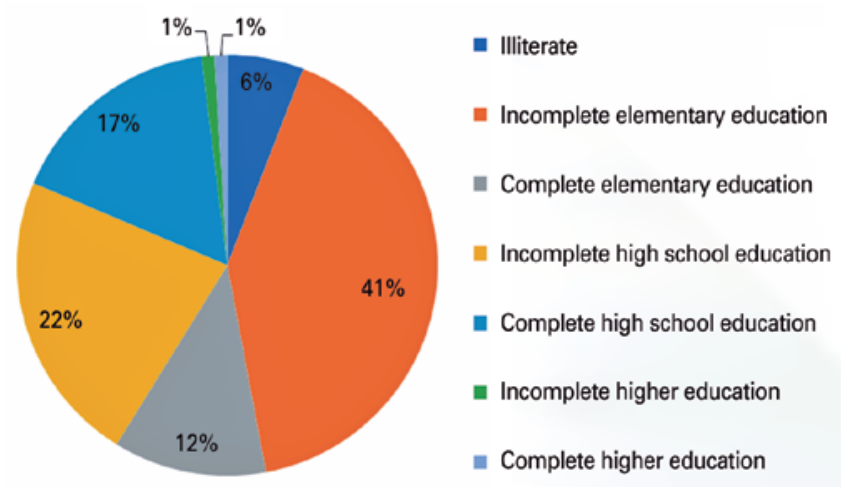

Figure 2. Distribution by educational attainment.

The occurrence of open fractures was greater in weekend days than weekdays (48.44\%) (Figure 3), but with no statistical significance. Most accidents occurred from 7 p.m. to midnight (42\%) (Figure 4), with statistical significance $(p<0.001)$ compared to the other periods of the day.

The frequency of consumption of alcohol, illegal drugs (marijuana, cocaine, crack, heroin, ecstasy, solvents), and both in the 6 hours before the accident was $12.84 \%, 1.83 \%$, and $3.66 \%$, respectively. With regard to illegal drugs, two patients (1.83\%) reported marijuana consumption, and four (3.66\%) reported use of alcohol and cocaine in the 6 hours before the trauma.

In relation to fracture severity, there was a predominance of Gustilo and Anderson ${ }^{(4)}$ type II fracture (moderate degree of contamination and skin injury $>1 \mathrm{~cm}$ and $<10 \mathrm{~cm}$ ) $(42.6 \%)$, followed by IIIA type fractures (high degree of contamination with skin injury $>10 \mathrm{~cm}$, with possibility of primary coverage) (Figure 5). Furthermore, 22.06\% of fractures had other trauma-associated injuries, such as close fractures (11\%), skin injuries in other topographies (7.4\%), abdominal trauma (1.83\%), and traumatic brain injury (1.83\%).

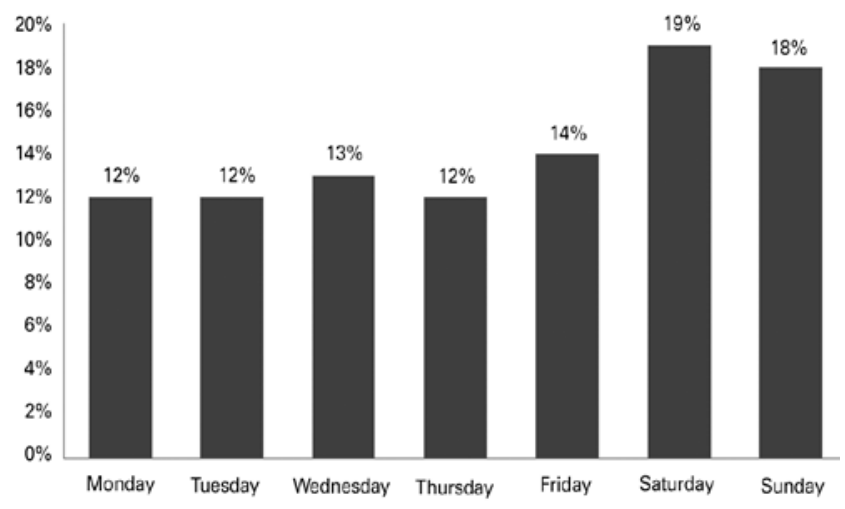

Figure 3. Distribution by day of the week.

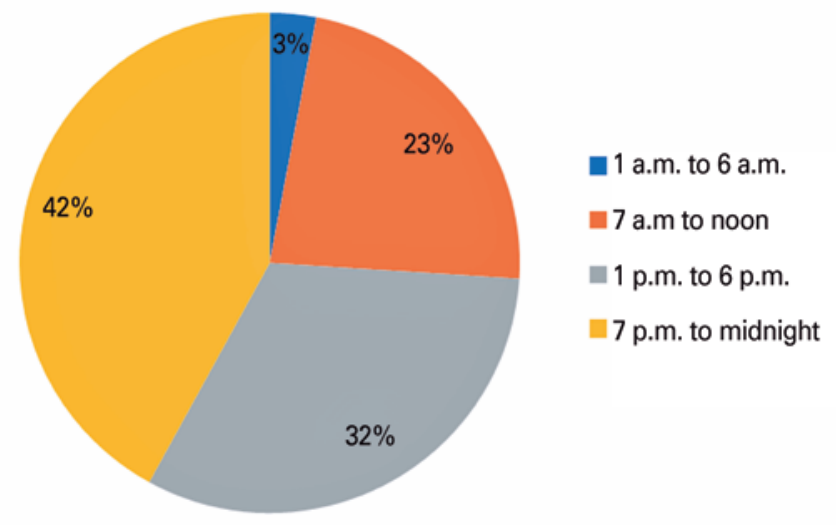

Figure 4. Distribution by time of day.

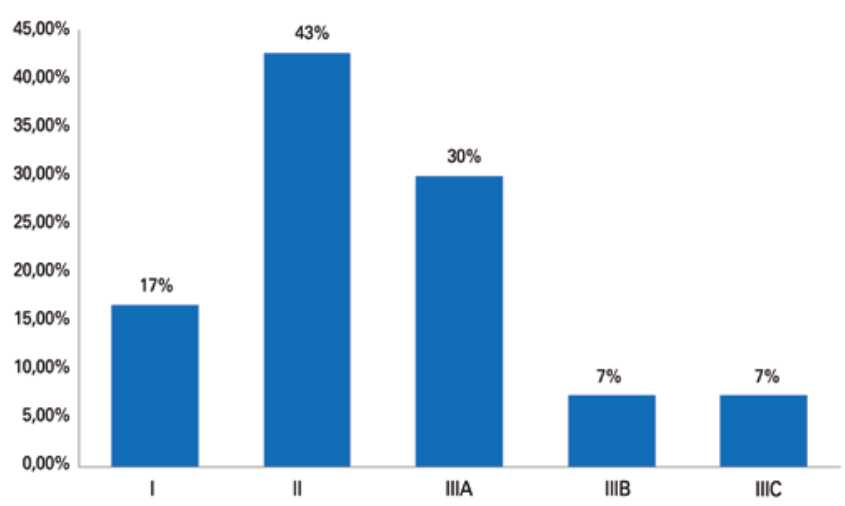

Figure 5. Distribution according to Gustilo and Anderson classification (Type I, II, IIIA, IIIB, IIIC). 
The Mobile Urgent Care Service (Serviço de Atendimento Móvel de Urgência, SAMU) was the responsible for pre-hospital care and transportation to the ER in $56.72 \%$ of the cases, followed by the fire brigade (35 cases; $32.16 \%$ ). Furthermore, $7.89 \%$ of patients arrived at the PS using their own mean of transportation, and $3.21 \%$ of them were rescued by the air services of the military police.

The type of treatment implemented in all cases (100\%) involved antibiotic therapy, care of damaged soft tissues, appropriate cleaning, debridement, and fracture stabilization. The most frequent method of permanent bone stabilization was osteosynthesis (internal fixation) (56.45\%), followed by external fixation (33.34\%). Primary amputation was required in $3.7 \%$ of the cases. Permanent conservative treatment of fractures through immobilization (plaster cast sprints, plastering) was conducted in $6.51 \%$ of the cases.

Mean length of hospital stay was 8.57 days, and the rate of early infection was $7.4 \%$ in the first 7 days of fracture.

\section{Discussion}

It is assumed that, currently, the incidence of lower limb open fractures account for $40 \%$ of overall fractures ${ }^{(1,9)}$. Previously published studies found percentage variations in the occurrence of open fractures of foot and ankle with regard to the other body segments. Fractures of the distal tibia accounted for less than $1 \%$ of lower limb open fractures ${ }^{(5,13,14)}$. The percentage of open ankle fractures ranged from $4.8 \%$ to $11.27 \%$ of open fractures, whereas foot fractures ranged from $4.91 \%$ to $13.2 \%(5-8)$.

Other studies found that tibial pilon fractures associated with ankle fractures were present in $17 \%$ of the cases, and in $10.5 \%$ when associated with fractures of foot and ankle ${ }^{(13,15)}$.

In the current study, the percentage of open fractures of foot and ankle was $15.6 \%$, a result similar to that of previously published papers ${ }^{(1,5-9,11)}$.

The implemented treatments were based on the current guidelines for open fractures, which establish that care should be initiated as early as possible at the site where the trauma occurred, with prompt wound isolation, limb immobilization, and hemorrhage control. Broad spectrum antibiotic therapy is recommended according to the degree of contamination and extent of skin injury, as proposed by the Gustilo and Anderson Classification ${ }^{(11)}$. In most cases, first-generation cephalosporins were administered aiming at both gram-positive and gram-negative germs. In selected cases with intense contamination and extensive skin injuries $(>10 \mathrm{~cm})$, i.e., Gustilo and Anderson type III fractures ${ }^{(11)}$, the addition of aminoglycosides aimed at gram-negative germs is recommended, and was implemented in the analyzed cases $^{(6-8,11,12,16,17)}$.
In the current study, the percentage of early infections (first 7 days) was $7.4 \%$, results that differ from those of other studies from the national literature, which found percentages of $13.24 \%, 18.80 \%$, and $23.7 \%$ for open fractures in general ${ }^{(18-20)}$, and most infections were observed in open fractures classified as Gustilo and Anderson type $\mathrm{II}^{(18-22)}$. It is inferred that our results were lower than those observed in the literature due to the higher percentage of less severe fractures in the current study ( $42 \%$ of Gustilo and Anderson type II open fractures); additionally, most study were prospective, with follow-up duration longer than 6 weeks ${ }^{(18-22)}$. In the study with the highest percentage of infections (23.7\%), it was found that this high percentage was associated with severity of soft tissue injuries and delayed orthopedic treatment ${ }^{(22)}$. Similarly, the study by Fernandes et al. found a statistically significant increase in infections rates for more severe fractures and that had their treatment delayed by 6 hours after trauma ${ }^{(18)}$.

In order to minimize the risk for infection, timely treatment is performed with complete debridement, in which all foreign bodies and contaminated tissues, or those with suspected avascularization, are systematically removed, and death spaces and hematomas are minimized(13,17-22).

Patients underwent safe skeletal stabilization, with the recovery of limb length, a measure that enable to reestablish the appropriate soft tissue tension, in addition to improving circulation and facilitate venous and lymphatic return, thus favoring edema reduction ${ }^{(13,17-22)}$.

According to the literature, plaster and traction devices are used less frequently in patients with open fractures $(13,18,20)$, a finding consistent with the results obtained in the present study. Plaster devices hinder wound inspection and dressings, which may compromise early detection of ongoing compartment syndrome, as well as presence of skin necrosis, bullae, and infections ${ }^{(13,18,20)}$.

External fixators are used mainly as temporary stabilizers, with conversion to internal fixation being performed at the appropriate time, provided there are no contraindications. Permanent treatment with an external fixator may be suggested if the patient has a stable fracture configuration, good quality reduction and circumferential contact ${ }^{(13,18,21-24)}$.

\section{Conclusion}

This epidemiological study allowed us to characterize the pattern of open fractures of the ankle and foot, as well as patients' socioeconomic characteristics, and presence of associated injuries.

Male young adults were the most affected by these fractures, and traffic accidents were the leading cause. Most patients had an educational attainment of complete elementary education. Most fractures were classified as Gustilo and Anderson type II.

Authors' contributions: Each author contributed individually and significantly to the development of this article: LPC *(https://orcid.org/O000-0001-61060101) Reviewed bibliography, data collection, wrote the paper, interpreted the results of the study, participated in the review process; LASGF *(https:// orcid.org/0000-0002-5765-2304) Reviewed bibliography, collected the data, interpreted the results of the study, participated in the review process; JMM *(https://orcid.org/0000-0001-6039-4599) conceived and planned the activities that led to the study, interpreted the results of the study, participated in the review process; SDSP *(https://orcid.org/0000-0001-5957-527X) conceived and planned the activities that led to the study, reviewed bibliography, wrote the paper, interpreted the results of the study, participated in the reviewing process, participated in the review process; MAGR *(https://orcid. org/0000-0002-7424-9074) conceived and planned the activities that led to the study, interpreted the results of the study, participated in the review process. All authors read and approved the final manuscript. *ORCID (Open Researcher and Contributor ID) iD). 


\section{References}

1. Lange RH, Bach AW, Hansen ST, Johansen $\mathrm{KH}$. Open tibial fractures with associated vascular injuries: prognosis for limb salvage. J Trauma. 1985;25(3):203-8.

2. Sousa RLB, Sousa GS, Monroe KMCM, Pereira MGS. Injury accident reporting at a public hospital in the Brazilian Amazon. Rev Bras Promoç Saúde. 2017;30(1): 64-71.

3. Andrade LM, Lima MA, Silva CHC, Caetano JA. Motorcycle accidents: characteristics of the victims and accidents at a hospital in Fortaleza - CE, Brazil. Rev Rene, Fortaleza. 2009; 10(4):52-9.

4. Trevisol DJ, Bohm RL, Vinholes DB. Epidemiological profile of patients victims of traffic accidents treated in theemergency room of Hospital Nossa Senhora da Conceição in Tubarão,Santa Catarina state, Brazil. Rev Scientia Médica. 2012;22(3):148-52.

5. Cunha FM, Braga GF, Drumond Júnior SN, Figueiredo CTO. [Epidemiology of 1,212 open fractures]. Rev Bras Ortop. 1998; 33(6):451-6.

6. Prata Filho C, Mibielli MAN, Silos SS. Epidemiology of exposed fractures in the Clinic Hospital of Teresópolis - RJ. Rev Fac Med Teresópolis. 2018;2(2):113-23.

7. Guimarães RNO, Gurgel BEM, Valente NC, Maia FSC, Conceição TF. [Open fractures: epidemiological characterization of patients treated at a hospital in the Amazon]. Rev Cient Multidisc Nucl Conhec. 2009;6(4):117-31.

8. Arruda LRP, Silva MAC, Malerba FG, Fernandes MC, Turíbio FM, Matsumoto $\mathrm{MH}$. Open fractures: prospective and epidemiological study. Acta Ortop Bras. 2009;17(6):326-30.

9. Court-Brown CM, Brewster N. Epidemiology of open fractures. In: Court-Brown CM, McQueen MM, Quaba AA, editors. Management of open fractures. London: Martin Dunitz; 1996. p. 25-35.

10. Brumback RJ. Open tibial fractures: current orthopedic management. Instr Course Lect. 1992;41:101-17.

11. Gustilo RB, Anderson JT. Prevention of infection in the treatment of one thousand and twenty-five open fractures of long bones: retrospective and prospective analyses. J Bone Joint Surg Am. 1976;58(4):453-8.

12. Worlock P, Slack R, Harvey L, Mawhinney R. The prevention of infection in open fractures: an experimental study of the effect of fracture stability. Injury. 1994;25(1):31-8.
13. Jaña Neto FC, Canal MP, Alves BAF, Ferreira PM, Ayres JC, Alves R. Analysis of the characteristics of patients with open tibial fractures of Gustilo and Anderson type III. Rev Bras Ortop. 2016; 51(2):143-9.

14. Court-Brown CM, Christie J, McQueen MM. Closed intramedullary nailing. Its use in closed and type I open fractures. J Bone Joint Surg Br. 1990;72(4):605-11.

15. Santos LFS, Fonseca JMA, Cavalcante BLS, Lima CM. Epidemiologic of orthopedic trauma study in a public emergency. Cad Saúde Coletiva. 2016;24(4):397-403.

16. Melcher GA, Hauke C, Metzdorf A, Perren SM, Printzen G, Schelegel $U$, et al. Infection after intramedullary nailing: an experimental investigation on rabbits. Injury. 1996;27 Suppl 3:SC23-6.

17. Moehring HD, Gravel C, Chapman MW, Olson SA. Comparison of antibiotic beads and intravenous antibiotics in open fractures. Clin Orthop Relat Res. 2000;(372):254-61.

18. Fernandes MC, Peres LR, Queiroz Neto AC, Lima Neto JQ, Turíbio $\mathrm{FM}$, Matsumoto $\mathrm{MH}$. Open fractures and the incidence of infection in the surgical debridement 6 hours after trauma. Acta Ortop Bras. 2015;23(1):38-42.

19. Oliveira R, Cruz L, Matos M. Comparative accuracy assessment of the Gustilo and Tscherne classification systems as predictors of infection in open fractures. Rev Bras Ortop. 2018;53(3):314-8.

20. Guerra MTE, Gregio FM, Bernardi A, Castro CC. Infection rate in adult patients with open fractures treated at the emergency hospital and at the ULBRA university hospital in Canoas, Rio Grande do Sul, Brazil. Rev Bras Ortop. 2017;52(5):544-8.

21. Müller SS, Sadenberg T, Pereira GJC, Sadatsune T, Kimura EE, Novelli Filho JLV. Epidemiological, clinical and micorbiological prospective study of patients with open fractures assisted at a university hospital. Acta Ortop Bras. 2003;5:158-69.

22. Matos MA, Nascimento JM, Silva BVP. Clinical and demographic study on open fractures caused by motorcycle traffic accidents. Acta Ortop Bras. 2014;22(4):214-8.

23. Norris BL, Kellam JF. Soft tissues injuries associated with highenergy extremity trauma: principles of management. J Am Acad Orthop Surg. 1997;5(1):37-46.

24. Pacolla CAJ. Open fractures. Rev Bras Ortop. 2001;36(8):283-91. 